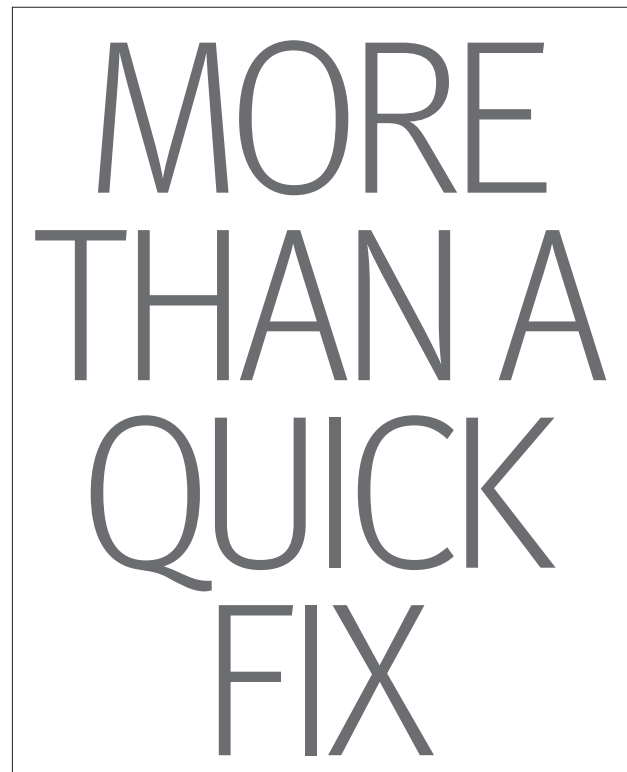

Despite its long use in the UK, prescribing heroin to misusers remains controversial. Tony Sheldon looks at the history and the evidence behind the increased prescribing in Europe

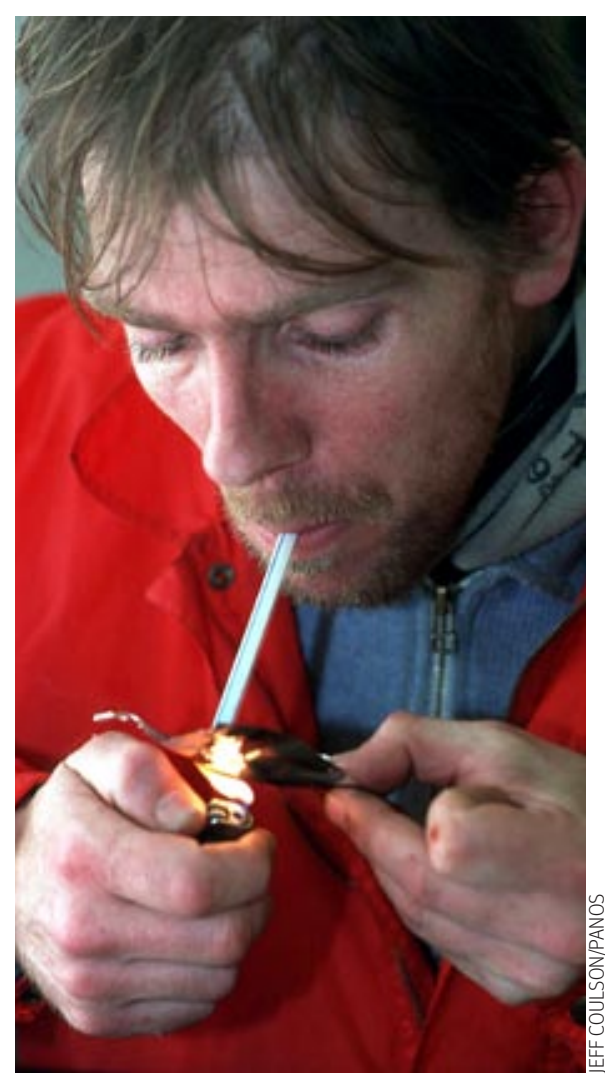

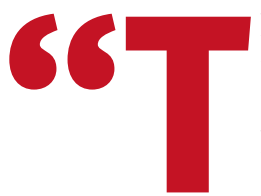

he past is a foreign country: they do things differently there." The famous line from L P Hartley's The Go-Between seems to sum up the medical prescribing of heroin to addicts. British medicine has a history of prescribing heroin, and the practice is now also largely accepted in Switzerland and the Netherlands. But use of the British system, as it was known abroad, in the United Kingdom has declined in favour of methadone maintenance-although not vanished completely.

It was 1926 when a government committee chaired by Humphry Rolleston, president of the Royal College of Physicians, advised it was legitimate medical practice to supply heroin to addicts for their maintenance. Only later was the practice restricted to doctors licensed by the Home Office. Past UK examples include the drug dependency clinic of London's University College Hospital, which prescribed injectable heroin during the 1970 s. ${ }^{1}$ Later, a team led by psychiatrist John Marks offered heroin on prescription in Widnes, Merseyside, in an attempt to restrict the spread of HIV.

However, by 1992 researchers estimated there were little more than 100 addicts prescribed heroin in the UK, while 17000 were prescribed oral methadone. ${ }^{2}$ Today the number of addicts in the UK regularly prescribed heroin is around 300, although the practice is enjoying a revival. ${ }^{3} \mathrm{~A}$ trial of supervised injecting, the randomised injecting opioid treatment trial (RIOTT), among 150 addicts at clinics in Brighton, London, and Darlington is set to run until 2008.

Similar relatively small scale trials of heroin assisted treatment have taken place in Canada, Spain, and Germany, where a multicentre trial with over 1000 participants took place between 2003 and 2005. However, only Switzerland and the Netherlands have had the political will to build a long term policy.

\section{Wider acceptance}

Switzerland was the first country to launch a large scale evaluation of heroin prescribing with a national cohort study running from 1994-6. It included more than 1000 people who were in poor health and who had repeatedly failed to benefit from conventional drug treatments during years of heroin addiction. They were offered controlled medical prescribing of heroin as part of a comprehensive programme of social and medical care.

By 1997, the Swiss federal authorities claimed a "substantial improvement" in addicts' physical and mental health and

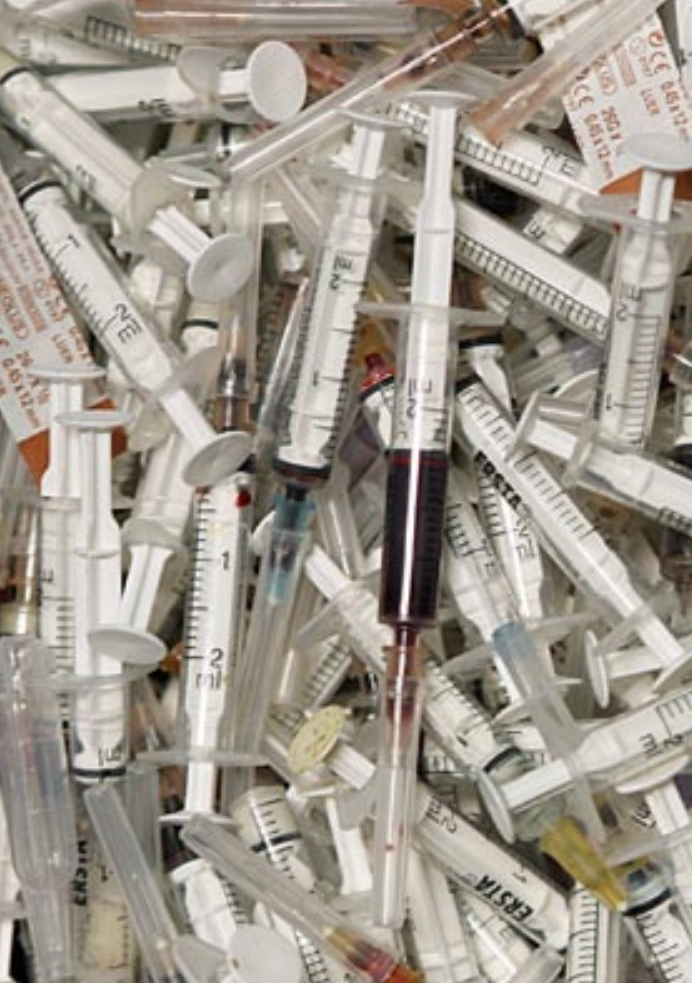

Will prescribing injectable heroin help reduce the problems the drug causes?

social situation as well as a $60 \%$ reduction in criminal behaviour. Clients' reported use of non-prescribed heroin fell significantly, and there were no deaths from overdose or complaints from local neighbourhoods. The study concluded that it is possible and clinically effective to provide injectable heroin at a clinic three times a day, seven days a week. ${ }^{4}$ Meanwhile public opinion swung behind the project. A referendum in September 1997 returned $71 \%$ in favour of heroin maintenance.

A later cohort study in 21 community outpatient treatment centres assessing more than 1600 heroin users between 1994 and 2000 concluded: "Heroin-assisted substitution treatment might be an effective option for chronically addicted patients for whom other treatments have failed." It showed $70 \%$ of users remained in treatment for more than a year with positive health and social outcomes. $^{5}$

Currently there are about 1300 addicts enrolled in 23 clinics across 16 Swiss cities. Criteria for inclusion include age 18 or older, being dependent on heroin for at least two years, having had two unsuccessful attempts at other treatment, and existence of severe medical, psychological, or social problems associated with heroin use.

Typically, people prescribed heroin are in their late $30 \mathrm{~s}$ and have been addicted to heroin for 10 years; a quarter are women and more than half will stay in treatment for two years or more. Of the up to 200 addicts who stop heroin prescribing each year, about $40 \%$ will transfer to methadone maintenance and a quarter will move to treatment based on abstinence. 
